\title{
Deterioration mechanism of steam-cured concrete subjected to coupled environmental acid and drying action
}

\author{
Guangcheng Long ${ }^{1,2}$, Youjun Xie ${ }^{1}$, Zhiyu Luo ${ }^{2}$, Lu Qu', John L. Zhou ${ }^{2}$ and Wengui Li $i^{*}$
}

\begin{abstract}
In order to investigate the deterioration mechanism of steam-cured concrete under severe environmental actions such as acid rain corrosion, salt corrosion, and cyclic thermal loading, accelerated corrosion tests were conducted in this study. Surface damage as well as deteriorative kinetics of steam-cured concrete and cement paste suffering from coupled acid-thermal actions was investigated by soaking-drying cycle experiments. The effects of mineral admixture, curing regime and corrosion condition on the durability were all comparatively studied, and the X-ray diffractograms and nanoindentation were applied to analyse the mechanism of corrosion deterioration. The results revealed that compared with the cementitious materials under standard curing, larger depth and faster corrosion were observed for steam-cured concrete and cement paste, which might be partly attributed to the lower content of hydrated production presented in steam-cured specimens. Besides, under acid solution soaking-drying cycle regime, there was significant higher corrosion depth compared to only soaking in acid solution. The corrosion depth under steam curing and soaking-drying condition increased by $156.68 \%$ and $44.17 \%$, respectively, compared with those under standard curing and only soaking treatment. In addition, fly ash effectively decreased the corrosion depth of steam-cured cement paste and concrete by $64.98 \%$ and $16.33 \%$, respectively.
\end{abstract}

Keywords: Steam-cured concrete, Corrosion deterioration, Acidic solution soaking-drying cycle, Corroded depth, Nanomechanical properties

\section{Introduction}

It is well known that concrete is one of the most widely used building materials in civil engineering infrastructures, including railway, highway, hydraulic engineering, industrial and civil architectures. However, concrete can be degraded or even be damaged by a number of physicochemical attacks when it is continuously exposed to severe environment with aggressive species and dramatic change of ambient humidity and temperature [1-4]. Such physicochemical attacks include acidic attack, carbonation, sulfate attack and others. Another significant attack is thermodynamic effect attributed to high

\footnotetext{
* Correspondence: wengui.li@uts.edu.au

${ }^{2}$ Center for Green Technology, School of Civil \& Environmental Engineering, University of Technology Sydney, Sydney, NSW 2007, Australia

Full list of author information is available at the end of the article
}

temperature changes between day and night, which may damage the internal microstructures [5].

Steam-cured concrete is cured in elevated temperature environment to obtain high strength in early age (generally less than 20 hours after casting), which can improve the efficiency of concrete production, reduce the construction time and generate significant economic benefits [6]. In some recent research, steam-cured is even combined with high early strength cement for faster strength growth [7-9], where the 1 day strength can typically reach $70 \%$ of the design strength [7]. Owing to above advantages, steam-cured concrete is commonly used in prefabricated elements of high-speed railway foundation structure in China, such as girder, track slab and sleeper. However, compared with normal concrete cured at room temperature, elevated temperature curing 
techniques may lead to heat-damage such as visible surface spalling and swelling deformation [10-13] as well as also higher capillary porosity, coarsening of pore structure, non-uniform distribution of hydration products in micro-scale [14-16]. As a result, the durability of steamcured concrete under severe environments may be worse than that of normal concrete. Negative effects of steam curing on long-term mechanical properties [17], durability properties such as surface resistivity and capillary absorption [15], Chloride ion resistance [18, 19] and sulfate resistance [20] have been reported. In the past decades, the durability of concrete structure has been a major concern globally. Extensive research has been carried out to investigate the physical and chemical interaction between concrete and different media including acid rain, sulfate salt and others, not only including the corresponding mechanisms and testing methods, but also involving factors influencing concrete deterioration and corresponding improvement measures to concrete durability [21-32]. However, the deterioration process of concrete is extremely complicated and there are still many problems need to be solved, such as degradation mechanism, effective rapid experimental method and so on. Especially, the deterioration behavior of steamcuring concrete under chemical-thermal condition is somewhat limited.

This research therefore aims to assess the deterioration behavior of steam-cured concrete subjected to the chemical-thermal coupled effect, by combining the component and structural features of precast steam-cured concrete elements used in high-speed railway and its typical service environments. The treatment circulation including soaking in acidic solution with sulfate ion $\left(\mathrm{SO}_{4}{ }^{2-}\right)$ and drying at $60^{\circ} \mathrm{C}$ was adopted to simulate the chemical-thermal coupled effect. The reason for this adoption is that in practice the acid rain and harsh temperature changes are main service environments of high-speed railway in South China. As mineral admixture may be beneficial to corrosion resistance [33, 34], the influence of fly ash (FA) and ground granulated blast-furnace slag (GGBS) on the corrosion resistance of cement paste and concrete was investigated. The findings are expected to provide new insight on the longterm service performance of prefabricated steam-cured concrete elements in high-speed railway.

\section{Experimental program}

\section{Raw materials}

Portland cement (P.I 42.5, denoted by C) was used in the experiments, which complies with the Chinese Standards GB8076-2008 and was manufactured by China United Cement Corporation. The specific surface area of cement is $347 \mathrm{~m}^{2} / \mathrm{kg}$. Class F fly ash comes from Xiangtan Power Plant of Hunan Province, in China. GGBS powder was also used, which was supplied by Changqing Building Materials Corporation, China. Table 1 lists chemical compositions of C, FA and GGBS. Aggregates used in the present paper include crushed limestone (G) and river sand (S) with a fineness modulus of 2.72. The crushed limestone has a continuous size of $4.75-20 \mathrm{~mm}$. Specific information of aggregates is provided in Table 2 and Fig. 1. Tap water was used as mixing water. Polycarboxylate superplasticizer with $26 \%$ water-reducing rate was added to obtain sufficient workability for fresh mixture (slump range from 30 to $50 \mathrm{~mm}$ ).

\section{Specimen preparation}

Three series of mixtures with compressive strength of $60 \mathrm{MPa}$, denoted as $\mathrm{A}, \mathrm{B}$ and $\mathrm{C}$ were designed and mixed on basis of the typical compositions of steamcured concrete used in high-speed railway construction. For comparison, the steam-cured paste with the same cementitious material and water as concrete A, B and C but without aggregate was also prepared. Besides, D was designed to investigate the performance of steam-cured cement paste by $30 \%$ of slag substitution. Mix proportions for concrete and paste specimens without aggregate were given in Table 3 . The effects of mineral admixture on the degradation of steam-cured concrete and paste subjected to chemical-thermal coupled effect were considered in this experiment.

Cementitious materials powders and aggregates were poured into forced-type mixer and mixed for $15 \mathrm{~s}$ firstly. Then, water and polycarboxylate superplasticizer were added into mixer. After mixing for $105 \mathrm{~s}$, freshly mixed concrete was taken out for slump test and casted into cube molds with the size of $100 \mathrm{~mm} \times 100 \mathrm{~mm} \times 100$ $\mathrm{mm}$, and then compacted on a vibration table. The paste was also mixed by the same mixing procedures as concrete specimens.

Table 1 Chemical compositions of cement, FA and GGBS (\% by weight)

\begin{tabular}{llll}
\hline Composition & Cement & Fly ash & Slag \\
\hline $\mathrm{SiO}_{2}$ & 20.76 & 55.25 & 31.01 \\
$\mathrm{Al}_{2} \mathrm{O}_{3}$ & 4.50 & 26.86 & 14.95 \\
$\mathrm{Fe}_{2} \mathrm{O}_{3}$ & 3.25 & 5.58 & 0.31 \\
$\mathrm{CaO}$ & 62.26 & 2.71 & 37.39 \\
$\mathrm{MgO}$ & 2.91 & 1.03 & 9.44 \\
$\mathrm{Na}_{2} \mathrm{O}$ & - & 0.86 & - \\
$\mathrm{K}_{2} \mathrm{O}$ & - & 2.43 & 0.46 \\
$\mathrm{Na}_{2} \mathrm{O}$ eq & 0.55 & - & - \\
$\mathrm{SO}_{3}$ & 2.81 & - & - \\
$\mathrm{f}-\mathrm{CaO}$ & 0.70 & - & - \\
$\mathrm{LOI}$ & 1.93 & 2.90 & 4.00 \\
\hline
\end{tabular}


Table 2 Properties of aggregates

\begin{tabular}{lllll}
\hline & $\begin{array}{l}\text { Specific } \\
\text { gravity }\end{array}$ & $\begin{array}{l}\text { Water } \\
\text { absorption } \\
\text { (wt.\%) }\end{array}$ & $\begin{array}{l}\text { Crushing } \\
\text { value } \\
\text { (wt.\%) }\end{array}$ & $\begin{array}{l}\text { Fineness } \\
\text { Modulus }\end{array}$ \\
\hline $\begin{array}{l}\text { Coarse } \\
\text { aggregate }\end{array}$ & 2.72 & 1.41 & 14.32 & 6.61 \\
$\begin{array}{l}\text { Fine } \\
\text { aggregate }\end{array}$ & 2.66 & 2.21 & - & 2.74 \\
\hline
\end{tabular}

After that, two curing procedures were carried out according to experimental designs respectively. One part of concrete and paste specimens was cured at fog chamber with temperature at $20 \pm 2{ }^{\circ} \mathrm{C}$ and humidity higher than 95\% after demolded at 1 day (abbreviated as standard curing specimens). Other specimens were cured at steam curing regime. In this regime, a total duration of $13 \mathrm{~h}$ is applied, which consist of $2 \mathrm{~h}$ precuring, $2 \mathrm{~h}$ heating, $8 \mathrm{~h}$ constant treatment at $60^{\circ} \mathrm{C}$ and $2 \mathrm{~h}$ cooling, as presented in Fig. 2. This steam curing regime was chosen as it enables concrete to achieve good early performance. Typically, the 1 day, 3 day and 7 day strength of the steam-cured reference sample are $40.51 \mathrm{MPa}, 45.85 \mathrm{MPa}$ and $51.33 \mathrm{MPa}$, respectively, which means that the specimen can achieve $65.91 \%$ of 28 day strength by just 1 day of curing and $83.52 \%$ of 28 day strength by 7 day of curing. After the above steam curing, the specimens were demolded and moved to fog chamber for standard curing (abbreviated as steam-cured specimens).

\section{Experimental methods}

In order to simulate actual chemical-thermal coupled effect of acid solution and elevated temperature that concrete elements subjected to, acidic solution was prepared by adding quantitative ammonium sulfate and nitric acid into tap water. The commercially available ammonium sulfate is the white crystal with a purity of $99 \%$, and the nitric acid is the light yellow liquid with mass fraction of $65-68 \%$. Both $\mathrm{H}^{+}$and $\mathrm{SO}_{4}{ }^{2-}$ in the prepared acidic solution with initial concentration of $0.01 \mathrm{~mol} / \mathrm{L}$. In order to keep $\mathrm{pH}$ value of solution constant during soaking process, $\mathrm{pH}$ adjustments with the frequency of twice daily at first week and then once daily at following 7 weeks were implemented by adding nitric acid. Besides, acidic solutions were altered once every 2 weeks. Two treatment regimes, acid soaking-drying cycle and continuous soaking, were employed for comparative analysis. The soaking-drying cycle regime is illustrated in Fig. 3 with a total of $24 \mathrm{~h}$ of treatment. This regime was adopted based on standard test method for sulfate corrosion resistance [35], which is considered as conforming to the actual exposure ambient condition of prefabricated element at hot weather. Correspondingly, the specimens for soaking regime were immersed in acidic solutions. Remarkably, before corrosion treatment, the specimens were moved into dry chamber and be dried at $60^{\circ} \mathrm{C}$ for $48 \mathrm{~h}$ when they have been cured for 26-day. The top and bottom face were sealed by epoxy resin coating and only lateral face is exposure. After that, the specimens were treated by above attack regimes.

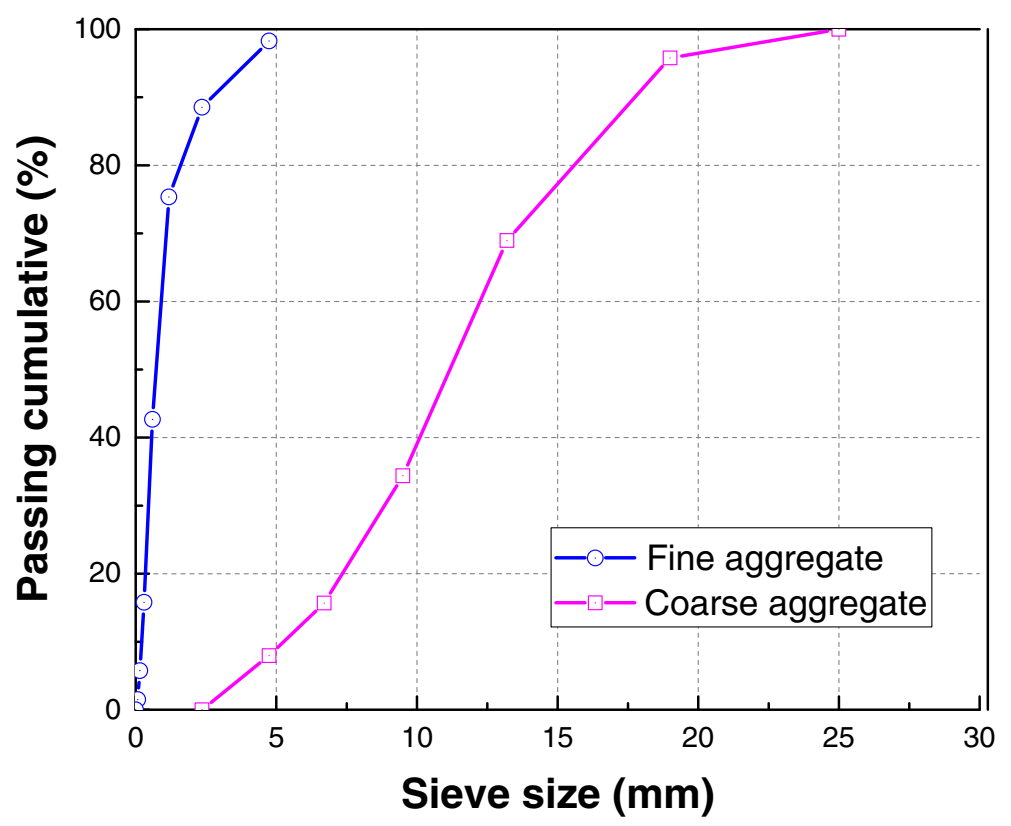

Fig. 1 Particle size distribution of aggregates 
Table 3 Mix proportions for concrete and cement paste (kg/

\begin{tabular}{|c|c|c|c|c|c|c|c|}
\hline Items & Cement & Fly ash & GGBS & Sand & Aggregate & Water & SP \\
\hline A & 450 & 0 & 0 & 660 & 1210 & 122 & 1.125 \\
\hline B & 315 & 135 & 0 & 660 & 1210 & 122 & 1.125 \\
\hline C & 315 & 90 & 45 & 660 & 1210 & 122 & 1.125 \\
\hline D & 315 & 0 & 135 & 0 & 0 & 122 & 1.125 \\
\hline
\end{tabular}

During the treatment process, the appearance and mass of specimens were measured at specific age. The variation of dimension of specimen can be calculated based on the relationship between mass, apparent density and volume (dimension) at different treatment ages. Then the corrosion depth $d$ can be obtained, which allows the following discussion about the deterioration kinetics of steam-cured concrete suffering acid solution soaking and drying cycles in term of the variation of corrosion depth with age. At the same time, the compressive strength variation was measured at different ages. The compressive strength development of concretes was tested at 4, 6, 8, 10 and 12 weeks, while the compressive strength loss rates of corroded concretes were calculated at 2, 4, 6 and 8 weeks according to Eq. (1).

$$
f_{l}=\frac{f_{N}-f_{C}}{f_{N}} \times 100 \%
$$

In which, $f_{l}$ is the compressive strength loss rate, $f_{N}$ and
$f_{C}$ are the compressive strength of specimens before and after corrosion, respectively.

Nanoindentation tests were conducted by NanoTest Vantage system to study the nanomechanical different of hydrated phases under different curing regime. Before conducting nanoindentation test, the cement pastes were subjected to grind and polish to achieve flat surface. The prepared samples with size of $10 \times 10 \times 10 \mathrm{~mm}$ were casted in epoxy resin and then ground by $240,400,800$, 1200 and 200 grits abrasive paper with each paper lasted for $6-8 \mathrm{~min}$. Afterward, they were polished by $1 \mu \mathrm{m}$ and $0.5 \mu \mathrm{m}$ oil-based diamond suspensions with small force for $30 \mathrm{~min}$ and $1 \mathrm{~h}$, respectively. During the polish process, residual particles one the polished surface were removed by ultrasonic cleaning with alcohol absolute for $3 \mathrm{~min}$. The $10 \times 10$ grid with a spacing of $20 \mu \mathrm{m}$ [36] for each indentation was set and load control mode was adopted for testing. In the process of testing, loading rate of $0.2 \mathrm{mN} / \mathrm{s}$ was imposed once the indenter tip contacted the specimen surface until reaching the prespecified maximum value of $2 \mathrm{mN}$ [37, 38]. The maximum load was held for $5 \mathrm{~s}$, then unloading with a constant speed of $0.2 \mathrm{mN} / \mathrm{s}$. Based on the recorded loading-depth curves as given in Fig. 4, the elastic modulus and hardness of different phases were obtained according to widely used calculation formulas [39-43]. Then probability density function (PDF) deconvolution technique [44, 45] was adopted for the statistical grid data to obtain the respective indentation modulus of phases in the hydrated system.

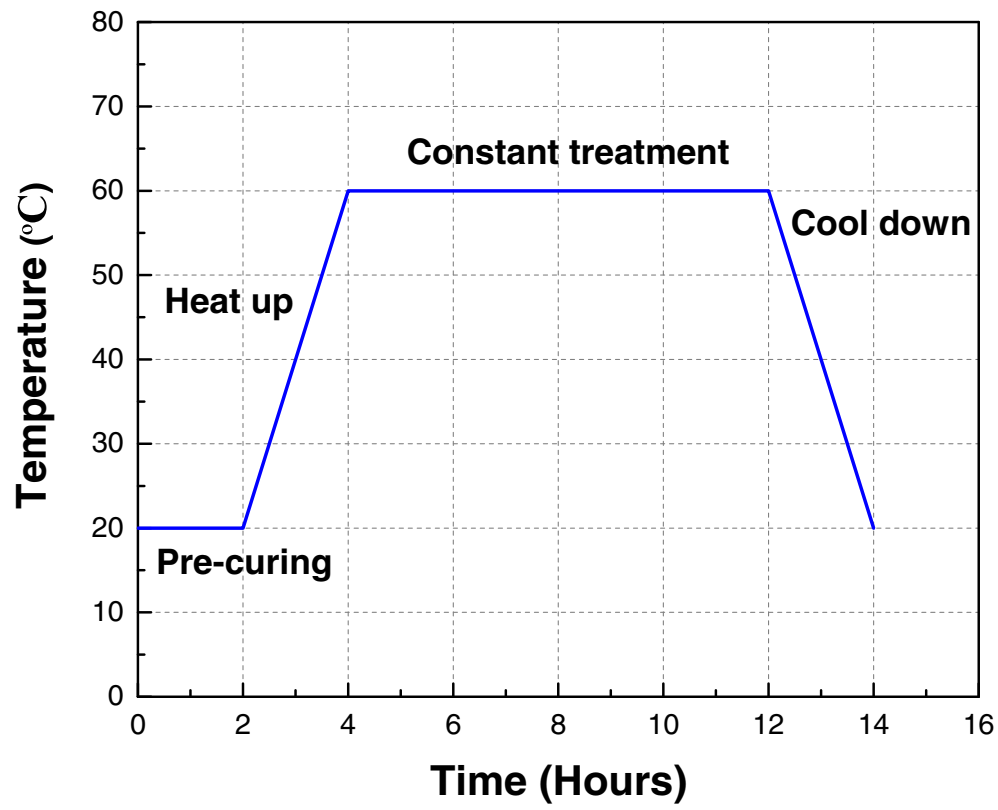

Fig. 2 Steam curing regime for concrete 


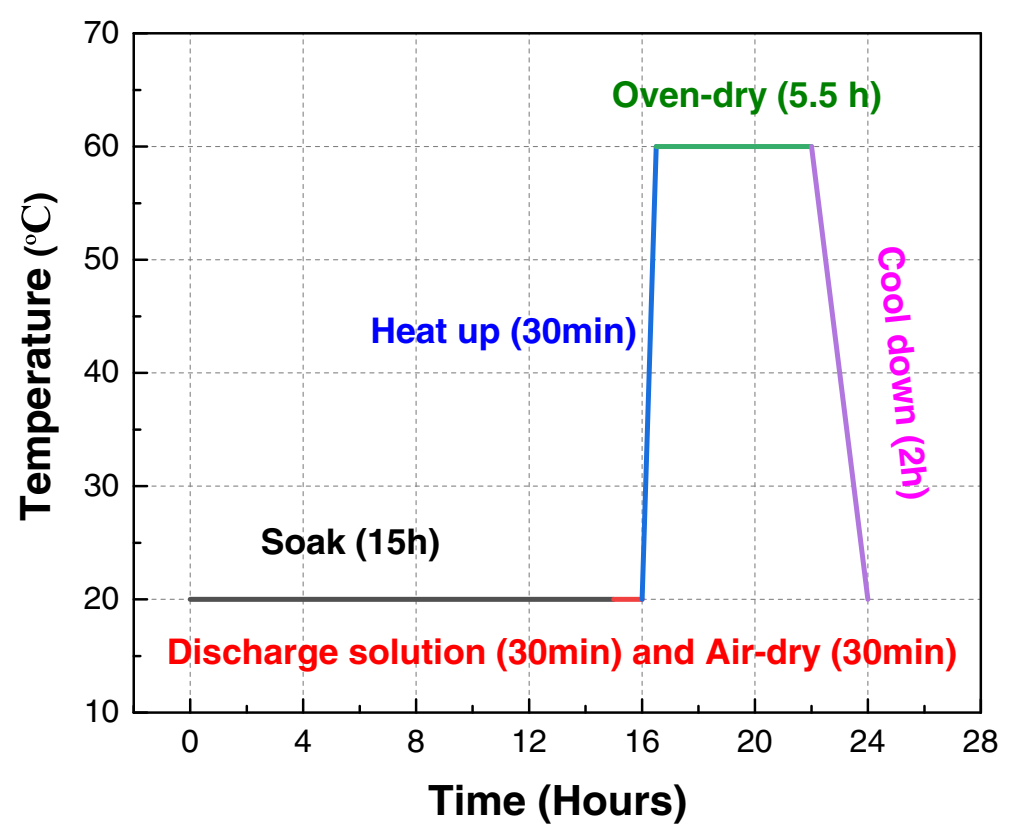

Fig. 3 Soaking-drying regime for concrete

\section{Results and discussion}

\section{Appearance change of cement paste and concrete}

The degradation of the specimens under different corrosion conditions could be preliminarily observed by the appearance change of it. The appearance of soakingdrying cycle corroded steam-cured paste and concrete incorporated with different mineral admixture are shown in Fig. 5, which indicated cracks in all cement paste specimens, which are especially obvious for cement paste without adding mineral admixture. Cracks decreases when FA or GGBS are incorporated in pastes, and more significant decrease of cracks can be found for cement paste with $30 \%$ FA substitution. Different from the pastes, the performance degradation of concrete is manifested as falling off aggregate and appearing of holes. However, the relative corrosion law of concretes with different mineral admixture is quite similar as the paste specimens. It is also the concrete without any addition

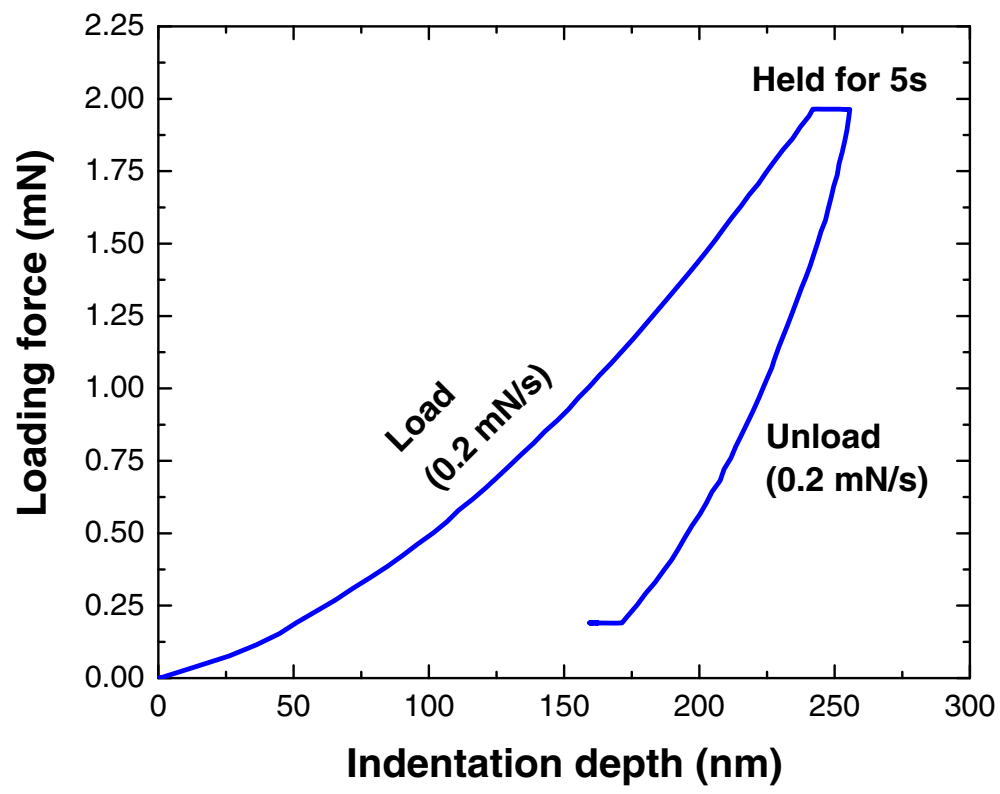

Fig. 4 Typical load-depth curve in nanoindentation test 


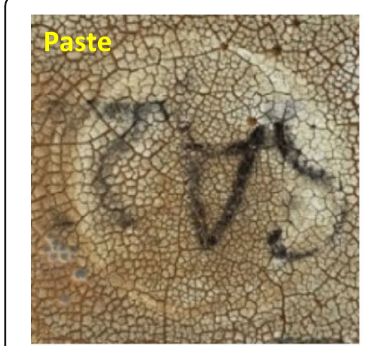

(a) $100 \%$ Cement

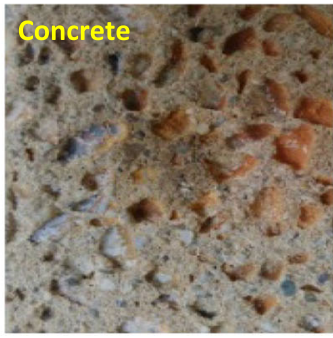

(a) $100 \%$ Cement

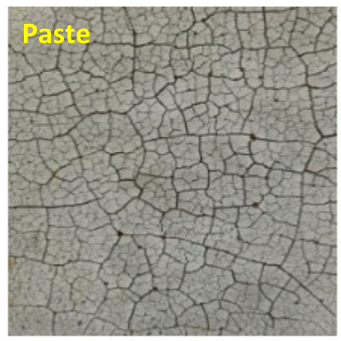

(b) $70 \% \mathrm{C}+30 \% \mathrm{FA}$

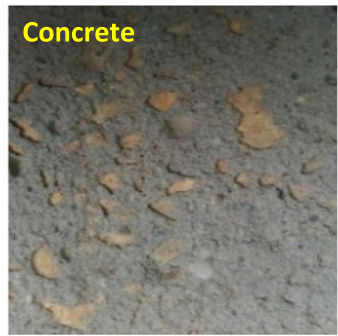

(b) $70 \% \mathrm{C}+30 \% \mathrm{FA}$

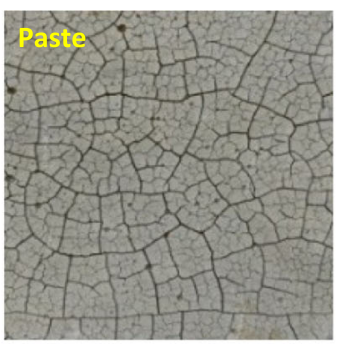

(c) $70 \% \mathrm{C}+20 \% \mathrm{~F}+10 \% \mathrm{GGBS}$

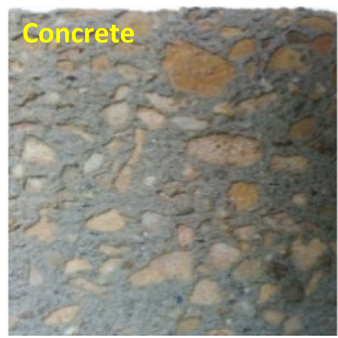

(c) $70 \% \mathrm{C}+20 \% \mathrm{FA}+10 \%$ GGBS

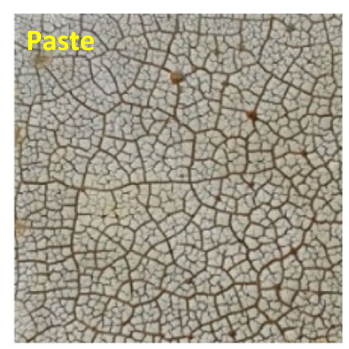

(d) $70 \% \mathrm{C}+30 \% \mathrm{GGBS}$

Fig. 5 Integrity performance of different admixtures during acid soaking-drying cycle for 8 weeks $(\mathrm{pH}=2)$

of mineral admixture exhibits the most severe appearance damage while the concrete with $30 \%$ FA maintains relatively more complete surface.
The influence of curing regime and corrosion condition on the appearance of cement paste and concrete are shown in Fig. 6. Concerning the paste specimens, after 8

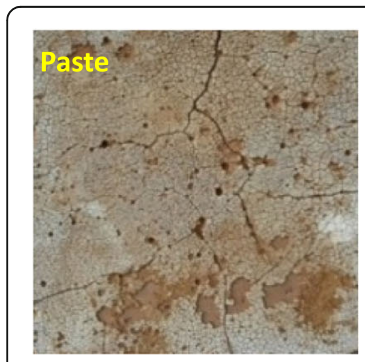

Soaking-drying cycle

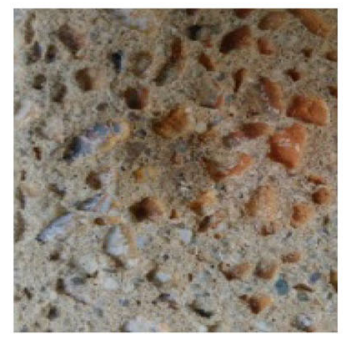

Soaking-drying cycle

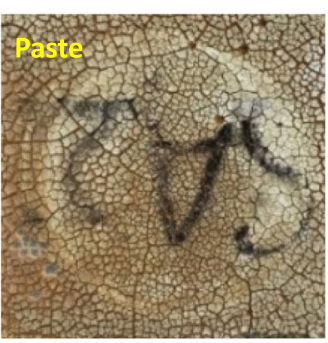

Only soaking

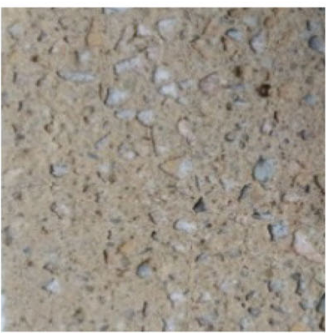

Only soaking

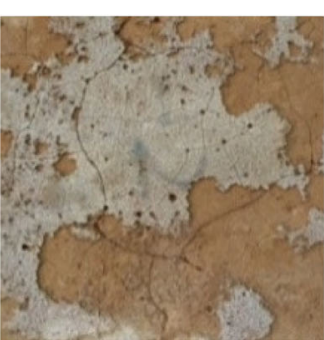

Soaking-drying cycle

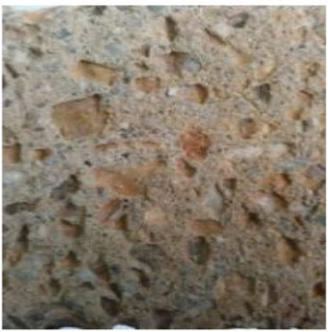

Soaking-drying cycle

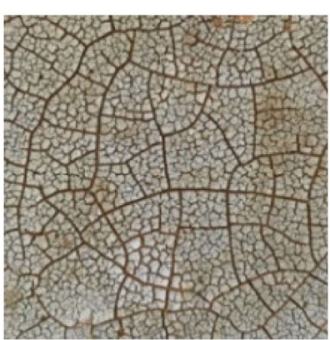

Only soaking

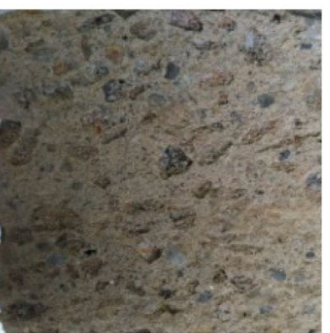

Only soaking

(a) Steam-cured specimen

(b) Standard-cured specimen

Fig. 6 Integrity performance of paste and concrete under different curing regimes and corrosion conditions (8 weeks, pH =2) 
weeks of treatment, corrosion and cracking deterioration clearly present at surface of them. There are dense cracks on the surface of specimens suffering from soaking. More serious surface damage can be observed for the specimens subjected to soaking-drying cycle. The surface layer of the specimens has fallen off and the inner layer is exposed. In addition, curing condition seems to also affect the surface corrosion of paste, greater corrosion is found for paste subjected to steam curing. Compared with the paste specimen, significantly different appearance change could be observed for concrete. After 8 weeks of corrosion treatment, there is a severe shedding of the paste on concrete, which is accompanied by the exposure of the aggregates. Some of the fine aggregate and coarse aggregate was even found to fall off from the specimen because the reduction of adhesive force, but no crevasse crack presented in concrete specimen. Similar to the paste specimen, there are also different influences of curing regime and acid treatment condition on the degradation of concrete. More severe appearance damage can be found for stream-cured concrete, and results also indicate that the soakingdrying cycle corrosion environment results in more serious surface degradation.

\section{Compressive strength degradation}

The compressive strength development of the steamcured concrete with different kinds of mineral admixture substitution is shown in Fig. 7. Obviously, all of the specimens experienced significant strength increase with curing ages. Compared with strengths at 28-day, the compressive strength of samples increased by around $15 \%$ at 84-day, in which it is the specimen incorporated with both FA and GGBS achieved the highest strength. It may be ascribed to the better activity of the GGBS than the FA, and hydration reaction will occur for GGBS

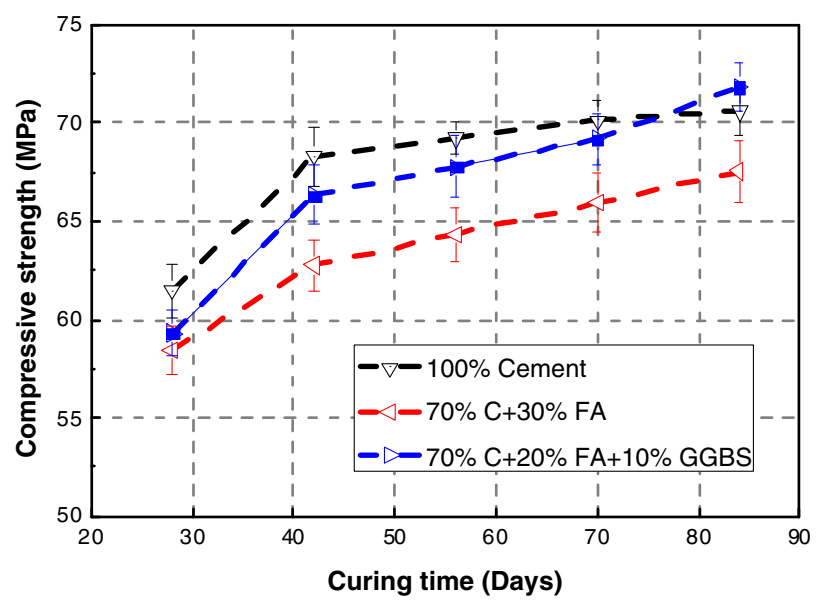

(a) Compressive strength development

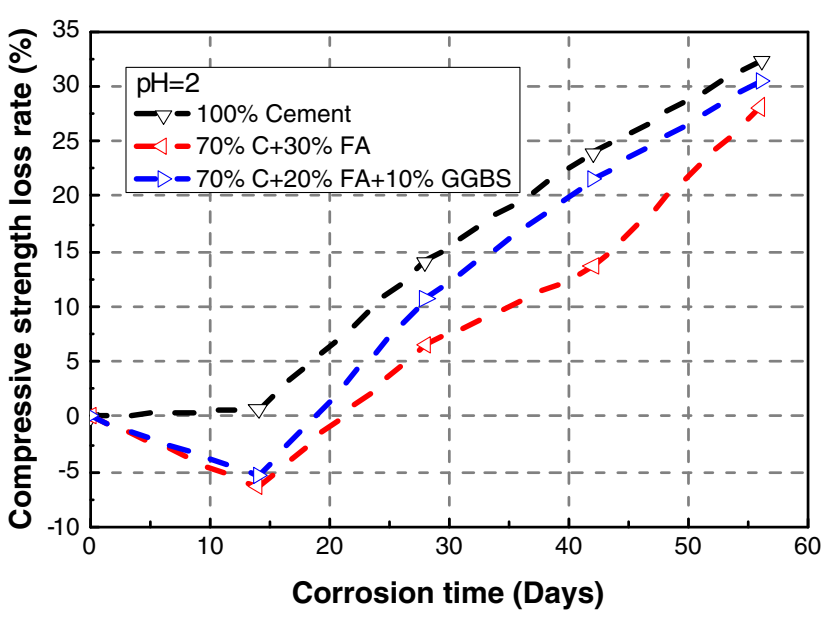

(b) Compressive strength degradation (soaking-drying cycle, $\mathrm{pH}=2$ )

Fig. 7 Influence of mineral admixture on the cube strength of stream-cured concrete 
specimen in the later stage. Although it is the specimen with 30\% FA displayed the lowest strength in all ages, the compressive strength loss rate of this specimen is significantly lower than others as depicted in Fig. 7(b). If the failure criterion is determined to be a loss of $20 \%$ of the original strength, specimens can be identified as failure on the 42-day except the specimen with $30 \%$ of FA. It should be noticed that the corrosion of concrete decreased the area of it, which would result in lower testing strength than the actual strength, and then overestimated strength loss rate. The easily shedding of surface concrete would also increase random test strength error between different specimens. However, according to the later results, the maximum corrosion of concrete is only $3 \mathrm{~mm}$. Hence, the deviation of strength calculation result is less than $6 \%$.

The influence of curing regime and corrosion condition on the compressive strength of concrete is revealed in Fig. 8. In terms of the compressive strength development, there is a similar 28-day compressive strength for specimens under standard curing and steam curing, but higher strengths present for standard-cured concrete in the later ages due to the stronger continuous hydration. The degradation of compressive strength of concretes under different curing condition and corrosion environment are shown in Fig. 8 (b). At the initial stage, the compressive strength of steam-cured concrete was slightly smaller than zero, which means small increment. The strength of concrete still underwent development at this stage, while the short time of corrosion didn't cause severe strength degradation, which resulted in a slight increase in strength in the corrosion environment. However, rapidly decrease of compressive strength occurred for all of the specimens. Compared with the concretes suffering from only soaking, there is higher compressive strength loss rate for the specimens subjected to both soaking and drying at all times. At the maximum corrosion days, 56-day, the compressive strength loss rate reached $28.4 \%$ for standard-cured specimen and 32.9\% for steam-cured specimen. Correspondingly, the compressive strength loss rate for standard-cured specimen and steam-cured specimen suffering from only soaking are only $21.8 \%$ and $27.4 \%$, respectively. Besides, Fig. 8 (b) also clearly revealed that the steam cured concretes experienced more severe strength loss than the standard cured concretes.

\section{Corrosion kinetics of hardened cement paste}

The degradation kinetics of concrete reflects the changing law of its performance with time during service life when subjected to a certain environmental condition. Many relevant achievements have been acquired by researchers [46-48]. Certainly, the degradation kinetic process of concrete is very complicated because many variable factors in practice are involved, including temperature, relative humidity, aggressive media etc. [16, $49,50]$. When specimen was placed into aggressive solution soaking or soaking-drying cycle treatment, the mass of specimen changed (reduction or increase) due to the media exchange between acidic solution and specimen and the physicochemical interactions. The interaction includes the dissolution of hydration products which play a critical role in mass loss, and chemical reaction between $\mathrm{SO}_{4}{ }^{2-}$ in solution and $\mathrm{Ca}^{2+}$ in specimen. Normally, the corrosion process of specimen suffering from acid solution attack is predominate and is from the surface to interior of concrete. Therefore, the change of corrosion depth of specimen with time is usually used to express the corrosive dynamic process of specimen. Based on the results obtained by Pavlik et al. [31], the corrosion depth of specimen can be expressed by a function of attack time as shown in Eq.(2).

$$
d=k \cdot t^{n}
$$

where $d$ is the corrosion depth (mm); $k, t$ and $n$ are the corrosive coefficient, corrosive time and power exponent. Among them, $k$ is the empirical parameter mainly affected by the ambient temperature, the concentration of $\mathrm{SO}_{4}{ }^{2-}$ and the components and pore structure of concrete; $n$ is the time index related to the corrosion time which refers to the chemical action duration of the concrete matrix and the corrosive substances. Furthermore, the corrosive velocity function can be obtained as shown in Eq. (3), which is the time derivative of Eq. (2).

$$
V_{d}=k^{\prime} \cdot t^{n-1}
$$

where $V_{d}$ is the corrosive velocity, $k$ is the corrosive rate coefficient and is equal to $k$ multiple $n$. As shown in Eq. (3), the corrosive velocity is a decreasing function with time $t$ if $n$ is less than 1 while the corrosive velocity is an increasing function when $n$ is larger than 1.0.

\section{Effects of mineral admixtures}

The corrosion depth of cement paste subjected to acid solution soaking with different mineral admixtures is depicted in Fig. 9. The real points are the experimental results of corrosion depth and the dotted lines are the corresponding fitting curves. The corrosive kinetics equation and its parameters calculated based on these data are shown in Fig. 9. Results indicate the corrosion depth of cement paste increased with the corrosion time and was well fitted with the degradation kinetics equation. It is also worth mentioning that the rise patterns of corrosion depth of cement paste were displayed in diversity with different mineral admixtures, with the plain paste had the largest corrosion depth and the paste with the substitution rate of Portland cement by $30 \%$ FA had 


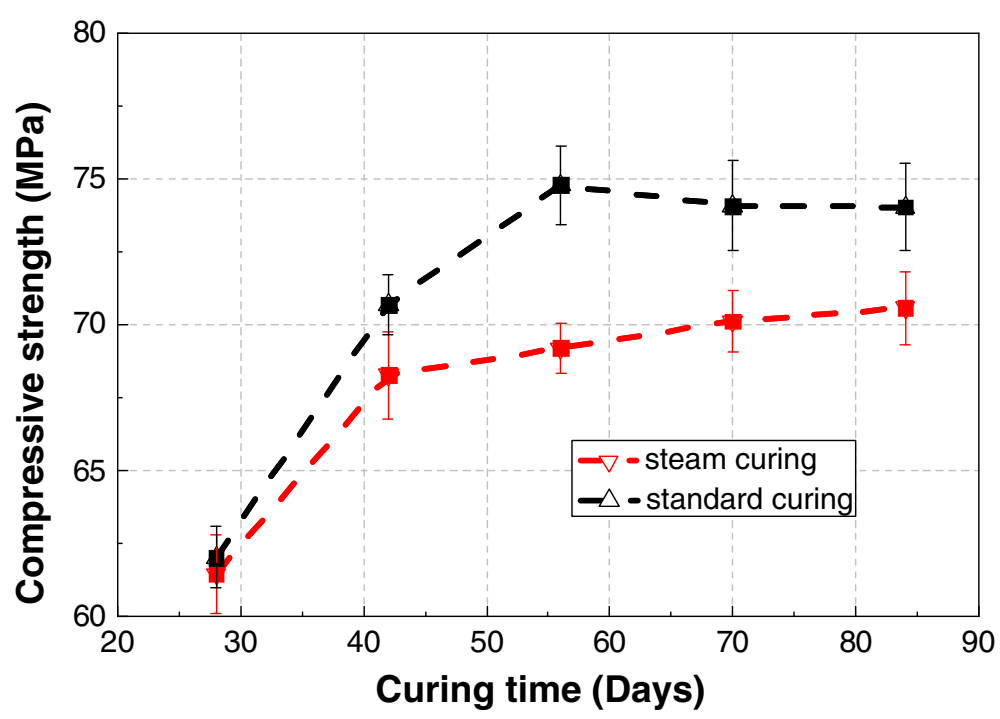

(a) Compressive strength development

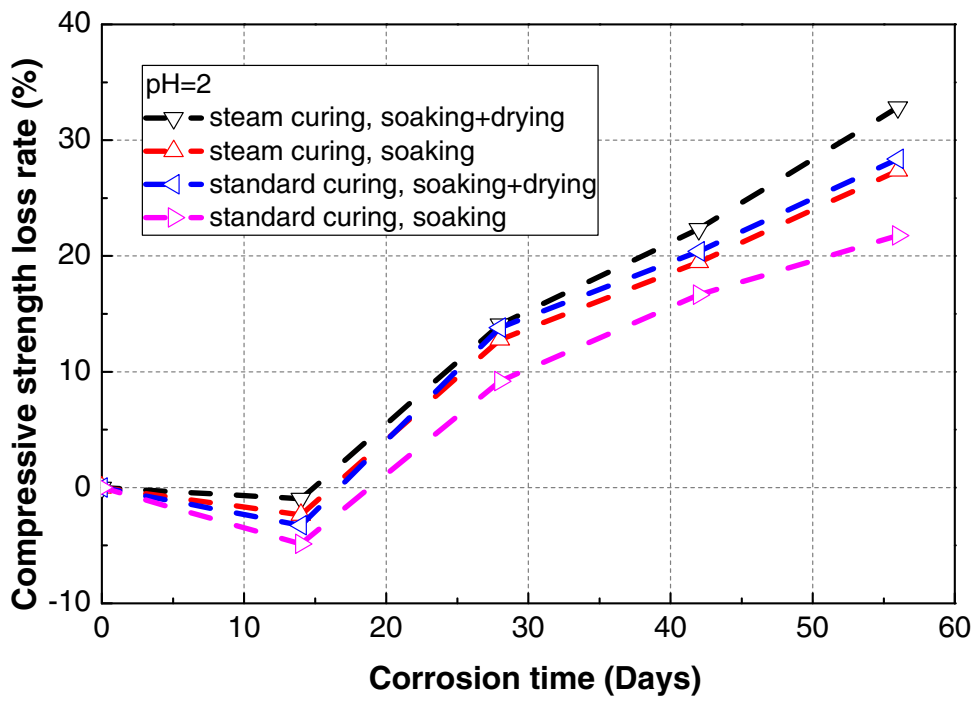

(b) Compressive strength degradation $(\mathrm{pH}=2)$

Fig. 8 Influence of curing regimes and corrosion conditions on the compressive strength of concrete

the minimum corrosion depth in all corrosion periods. Typically, the corrosion depth of cement paste at 56-day decreased around $64.98 \%$ by the incorporation of FA. The growth rate of corrosion depth of the paste with $30 \%$ GGBS and paste with 20\% FA and 10\% GGBS was moderate compared to the mentioned counterparts, with the former slightly larger than the latter. In general, the phenomenon clearly reflected that the admixtures of FA and GGBS have positive effect on the resistance of acid attack, especially the additive FA, which significantly enhances the anticorrosion ability of cement paste. This result is in line with the results of the appearance change and compressive strength loss of samples with different kinds of mineral admixture.

Further investigation on the corrosive kinetics equations showed that the quadratic value of correlation coefficient were both larger than 0.98 , which indicated that the Eq. (2) has excellent performance on the simulation of corrosion regularity and calculation of corrosion depth of paste subjected to acid solution soaking. Moreover, the time index $n$ of each specimens was lower than 1, leading to the convex curves of corrosion depth were observed in the tests. This means the corrosion rate of paste was gradually slowing down in the process, which may be due to the 


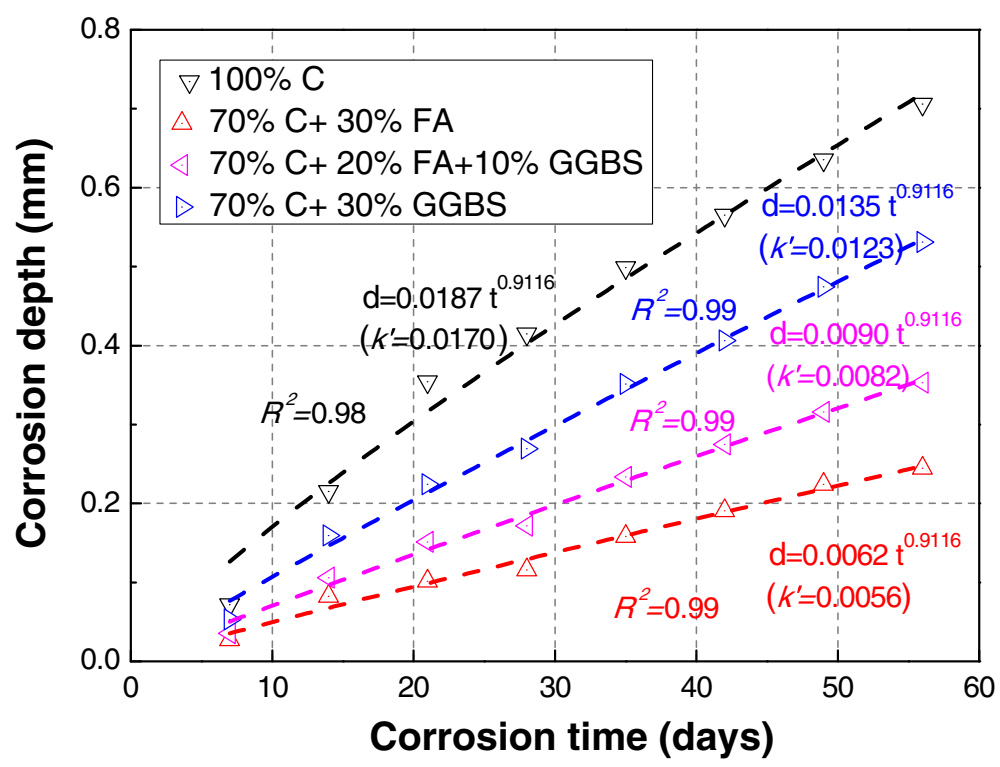

Fig. 9 Corrosion depth of steam-cured cement paste with different admixture during acid solution soaking $(\mathrm{pH}=2)$

continual hydration of cement paste and the block effect by the hydration products. Meanwhile, the velocity of $\mathrm{SO}_{4}{ }^{2-}$ entrance into the cement paste was also prevented by the corrosion products in the surface. Besides, for all four modified cement paste, their time index $n$ were totally identical except for the value of $k$, which has a maximum value in the field of plain paste and the least for the paste with 30\% FA. As shown in Fig. 9, the degradation coefficient $(k)$ was figured out by taking time derivation on both sides of the corrosive kinetics equation. It is the plain paste and 30\% FA modified paste achieved the largest value and lowest value, respectively.

\section{Effects of curing and corrosion methods}

The corrosive environments of acid solution soaking and the cycle of solution soaking and drying were applied on the standard-cured paste and steam-cured paste, respectively. As shown in Fig. 10, where the real points are the experimental results of corrosion depth and the dotted lines are the corresponding fitting curves. Besides, their corrosive kinetics equations and parameters are also displayed in details. In general, the corrosion depth of all types increased with the increase of corrosion time, and the steam-cured paste suffered more detrimental than standard-cured paste in corrosion depth during

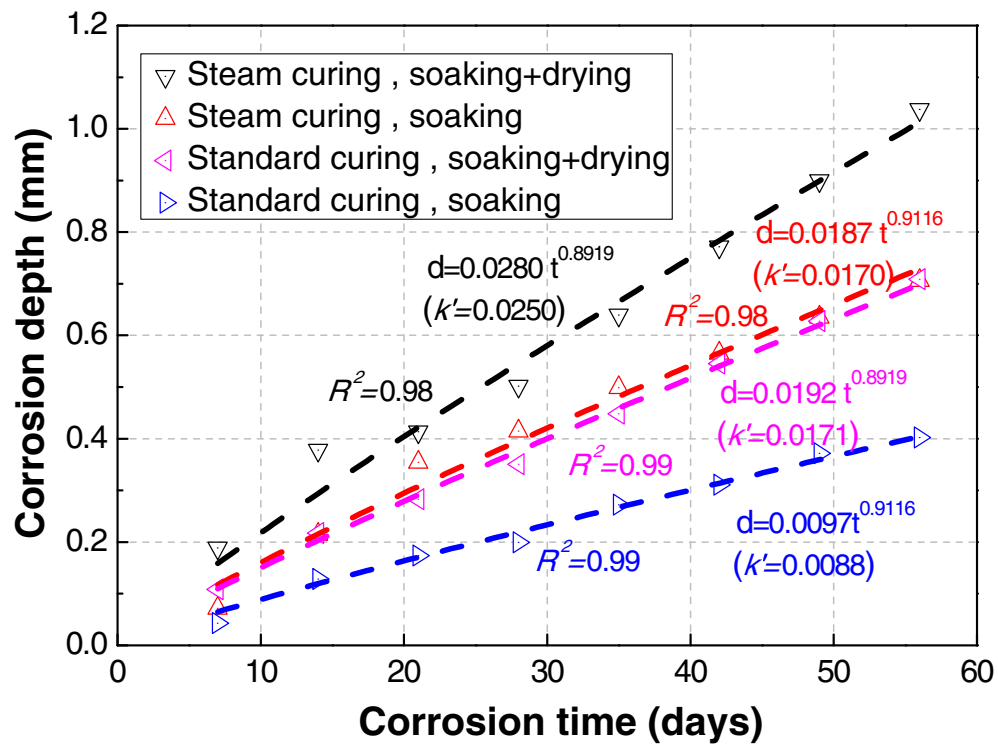

Fig. 10 The effects of corrosion condition and curing regime on corrosion depth of cement paste $(\mathrm{pH}=2)$ 
corrosion period. Moreover, as for the paste cured by the same curing methods, the corrosion condition of soaking and drying caused more corrosion depth than only soaking. Both of the conclusions indicated that the steam curing method and the soaking and drying corrosion way will enhance the corrosion rate of paste. At 56day, compared with the corrosion depth of specimen subjected to standard curing and soaking treatment, $156.68 \%$ increases of corrosion depth was found for the specimen under steam curing and coupling of soaking and drying condition.

Comparing the equations and their corresponding fitting curves in Fig. 10, the correlation coefficient is up to 0.98 , indicating the close functional relationship between the corrosion depth of paste and the corrosion time. It is remarkable that the time index $n$ in equations was all lower than 1 and greatly influenced by the corrosion condition. For the cement paste subjected to acid solution soaking and drying, which has the value of 0.8919 no matter the way of curing, and for its counterpart of only soaking, the index $n$ is gently larger with 0.9116. As for the kinetics equation coefficient, the values of steam-cured paste were significantly greater than standard-cured paste, and meanwhile, the corrosion method of soaking and drying was also positive on the corrosion rate. Similarly, the degradation rate coefficient $k^{\prime}$ could also be calculated according to the corrosion rate Eq. (3), which had an identical tendency with the kinetics equation coefficient. The degradation rate coefficient increased with the steam-cured method and the corrosion way of soaking and drying.

\section{Corrosion kinetics of concrete Effects of mineral admixtures}

In the acidic ambient of $\mathrm{pH}$ of 2 , the effects of $30 \% \mathrm{FA}$ and $20 \%$ FA coupled with $10 \%$ GGBS on the corrosion depth of steam-cured concrete are shown in Fig. 11. The real points are the experimental results of corrosion depth and the dotted lines are the corresponding fitting curves, in order to compare to the output of plain concrete. Their corrosive kinetics equations and related parameters are displayed next to the corresponding curves.

As depicted in Fig. 11, the corrosion depth of all specimens increased with the corrosion time. However, the concrete with the admixture of FA and GGBS or only FA caused decrease in corrosion depth, and achieved around $16.33 \%-18.81 \%$ reduction in depth after 56 soaking and drying cycles. Although similar corrosion depth were achieved by these two kinds of mineral admixture incorporation methods, the corrosive kinetics equations and its parameters still indicate that the concrete with $30 \%$ FA may have better corrosion resistance than the concrete with $20 \%$ FA and $10 \%$ GGBS. The reduced corrosion depth of mineral modified concrete is mainly due to the filling effect of FA and GGBS, which could improve the compactness of concrete and decrease the entrance of corrosive substance. Moreover, the additives altered the composition of the hydrated product by reducing the amount of $\mathrm{Ca}(\mathrm{OH})_{2}$, which also prevents the concrete from corrosion to some extent.

The kinetics equations with the correlation coefficient square $R^{2}$ up to 0.99 are shown in Fig. 11. The coefficient of kinetics equations of plain concrete is maximal with 0.01594 , and the value of concrete with FA is

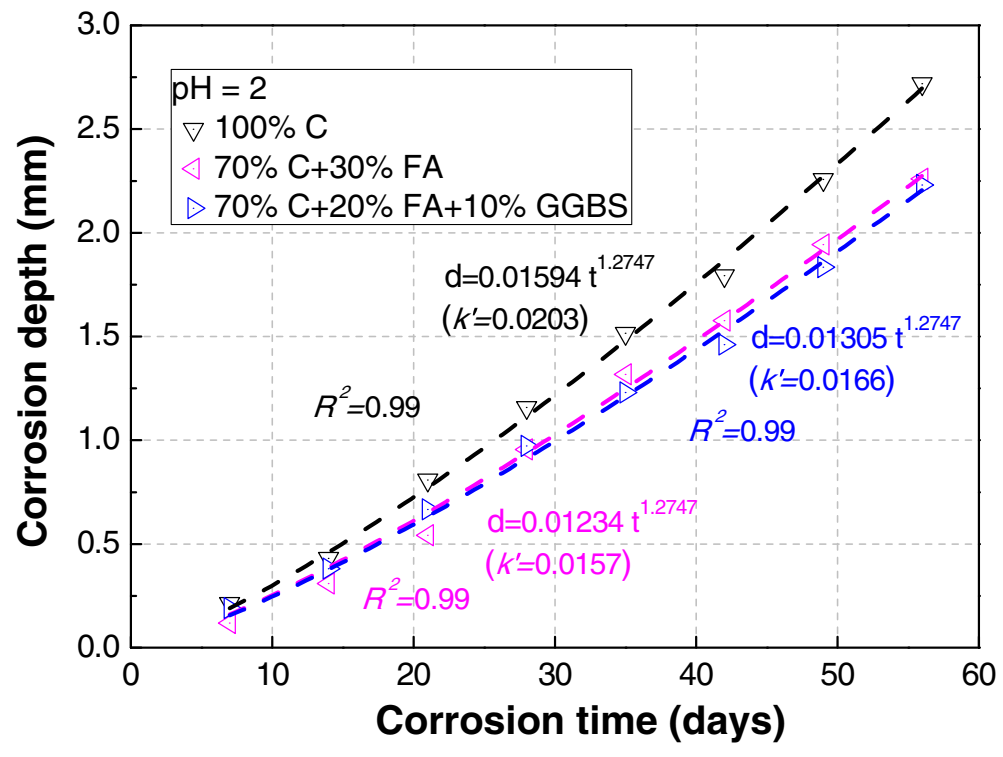

Fig. 11 Corrosion depth of steam-cured concrete with different admixtures (soaking-drying, $\mathrm{pH}$ =2) 
minimal with 0.01234 , while the time index of $n$ is 1.2747 for all specimens. Do not like the time index $n$ of cement paste, which lower than 1 , the index of concrete means the corrosion rate will be gradually increased with the corrosion time. The differences between paste and concrete may be due to the divergence of composition phase and the corresponding corrosion regulation. In general, the paste takes up nearly $30 \%$ in volume of concrete, which fills the porosity and wraps around the matrix. When the surrounded paste cracks and drops from the concrete, the nearby concrete coarse aggregates which is fixed by paste will be spalling too, leading the increase of measured corrosion depth. As a consequence, the corrosion rate of concrete is larger than the paste as described in the fitting curves.

\section{The effects of $\mathrm{pH}$ value of acidic solution}

The effects of acidic solution with different $\mathrm{pH}$ values on the corrosion depth of steam-cured concrete are described in Fig. 12. The fitting curves and corresponding corrosion kinetics equations are listed accordingly. It is significant that the $\mathrm{pH}$ value of acidic solution make huge influences on the corrosion depth of concrete, with the very fast corrosion rate in the $\mathrm{pH}$ of 1 solution and relatively low corrosion velocity in the solution with $\mathrm{pH}$ values of 3 and 4 . The corrosion depth even reached upper than $10 \mathrm{~mm}$ during the fourth week soaking in the $\mathrm{pH}$ of 1 solution, while only lower than $1.0 \mathrm{~mm}$ for the $\mathrm{pH}$ values of 2,3 and 4 at the same period. Obviously, the content of $\mathrm{H}^{+}$plays as the main corrosive irons in acidic solution exponentially increased with the lower $\mathrm{pH}$ value, leading to the more fierce reaction between $\mathrm{H}^{+}$and $\mathrm{Ca}(\mathrm{OH})_{2}$ in solution and thus the corrosion depth is unavoidably increased.

As depicted in Fig. 12, the correlation coefficient square $R^{2}$ of both fitting curves is close to 1 and the real tested results fits well with the corrosion kinetics equations. The coefficient of kinetics equation showed exponential decrease with the increased $\mathrm{pH}$ value of solution, ranging from 0.1407 to $7.0310^{-4}$. However, the values of time index $n$ were both equal to 1.292, which is different to the pattern of cement paste. The degradation rate coefficient $k^{\prime}$ could be calculated by the derivation on both sides of the kinetics equation. As shown in Fig. 12, the degradation rate was increased with the acidity degree in solution, especially for the solution of $\mathrm{pH}$ of 1 , which was almost ten times and even hundred times larger than its counterparts.

\section{Effects of curing and corrosion methods}

Figure 13 shows the corrosion depth of steam-cured and standard-cured concrete with the corrosion ambient of soaking and drying cycles and only soaking in acidic solution. In the corrosion ambient with $\mathrm{pH}$ of 2 , the corrosion depth of all concrete is increased with the corrosion time. Regardless of the curing methods, the corrosion depth of concrete subjected to soaking and drying cycles was higher than only soaking treated concrete. Moreover, for the same corrosion ambient, the steam-cured concrete had larger corrosion depth than standard-cured concrete, which indicates that both the steam-cured and soaking and drying cycles are detrimental to the anticorrosion ability of concrete. Under steam curing and soakingdrying condition, the corrosion depth of concrete increased around $44.17 \%$, compared with that under

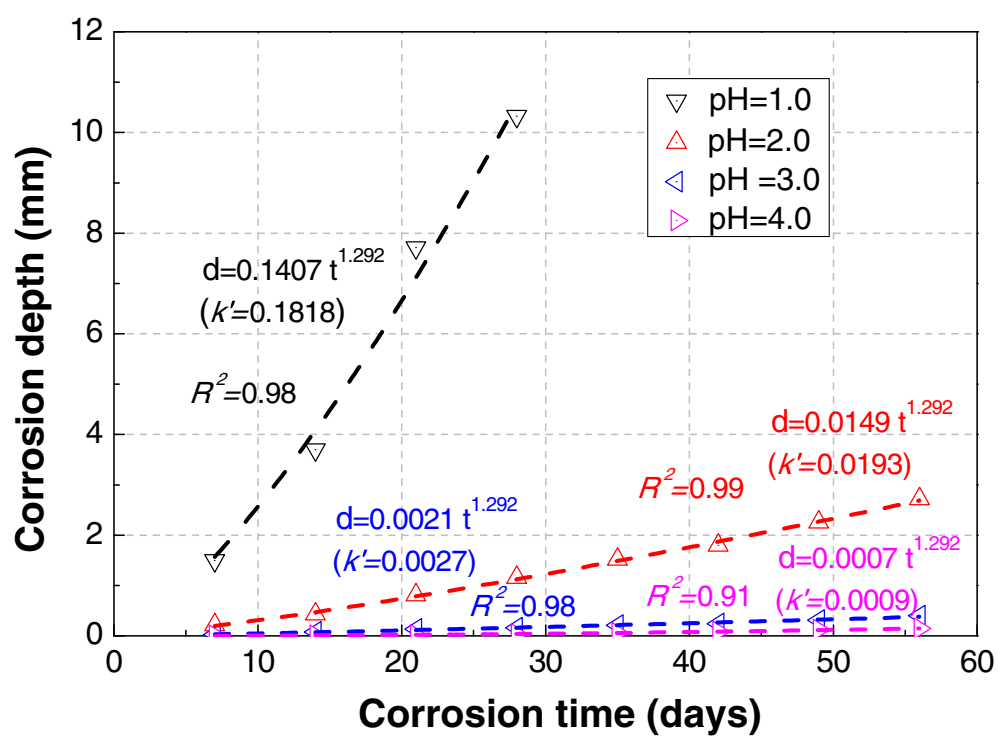

Fig. 12 Corrosion depth of steam-cured concrete in the acidic solution with different pH values 


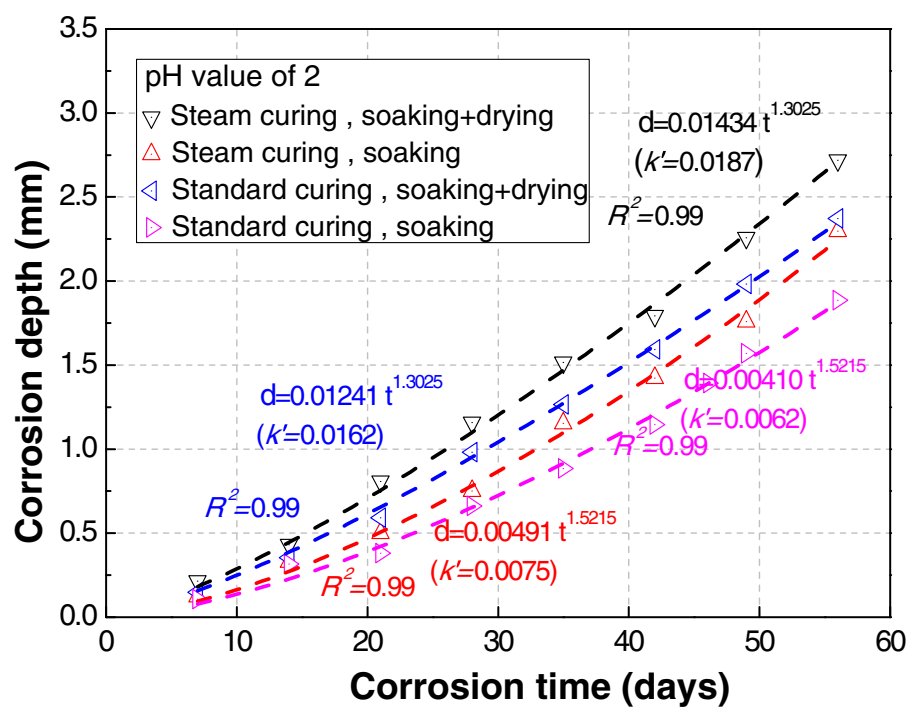

Fig. 13 The effects of corrosion condition and curing regime on corrosion depth of concrete $(\mathrm{pH}=2)$

standard curing and only soaking condition. Besides, the corrosion depth of concrete is found to be larger than the value of cement paste (Fig. 10), which indicates that the degradation rate of concrete is indeed larger than cement paste in the acidic solution conditions.

The corrosion kinetics equation with the correlation coefficient square $R^{2}$ of 0.99 indicates that it fits well with the real corrosion depth. The time index $n$ of the soaking and drying treated concrete is 1.3025 and for the only soaking treated concrete is 1.5215 regardless of the curing methods. It also indicated from Fig. 13 that the corrosion rate of concrete is gradually increased with the corrosion time.

In summary, the time index $n$ of concrete is larger than 1 , while the value is less than 1 for the cement paste. Normally, concrete consists of the cement paste and aggregate and the corrosion depth of concrete includes the spalling of cement paste and the aggregate. The size of inert aggregate ranges from 5 to $20 \mathrm{~mm}$ keeps bonds with others by the surrounded cement paste. When the cement paste is damaged by the corrosion and spalling, the bond forces between the aggregates decrease and gradually fall off from the concrete, causing the degradation rate of concrete faster than cement paste. Furthermore, with the increase of corrosion time in the mid-term stage of corrosion, the corrosion of cement paste is too severe to hold up the aggregate than ever before, which also brings up the increasing corrosion rate of concrete with the corrosion time.

\section{Mechanism analysis}

Cement hydrated products, such as $\mathrm{Ca}(\mathrm{OH})_{2}, \mathrm{C}-\mathrm{S}-\mathrm{H}$ gel and calcium aluminate hydrates are susceptible to attack by acids. Factually, hydrated cement compounds are stable only in solutions with high concentrations of $\mathrm{Ca}^{2+}$ and $\mathrm{OH}^{-}$. Hence, the acidic attack of concrete is essential an acidic-alkaline reaction between hydrated cement products and acidic ion [51-53]. Firstly, calcium hydroxide is attacked by $\mathrm{H}^{+}$or other acidic ion. It was proved that Portlandite is the first to dissolve at $\mathrm{pH}$ values below 12.6 corresponding to a saturated solution. Below $\mathrm{pH}$ values are accordingly corresponding to the stability limits of calcium silicate hydrate, calcium aluminate hydrates, etc. Once the $\mathrm{pH}$ value is lower than the stability limits, these cement hydrated products will lose calcium and degrade. Generally, the calcium from $\mathrm{Ca}(\mathrm{OH})_{2}$, other hydrated phases and unhydrated cement particles is either leached away by dissolution or produces an insoluble salt with acid ion. The corrosion process between hardened cement paste/concrete and acid solution is decided by the diffusion of aggressive acid ion through solution to the surface of specimen and by the chemical processes at the surface itself. When the layer of corrosive products begins to form, the process becomes partially diffusion controlled (diffusion through the corroded layer). Finally, when the corroded layer acts as a protection coating to the transport of aggressive ion, the process will become completely diffusion controlled. Then, the corrosion process is greatly influenced by the dimension and/or diffusion resistance of the barrier layer. Therefore, corrosion occurred once the specimens contacted with the acid solution, which leads to decrease of mass and thus increase of the corrosion depth. It was found that the extent of acid attack expressed by calcium dissolution, by acid consumption or by the thickness of the corroded layer was a linear function as shown in Eq.(2) [54]. The experimental results are consistent with diffusion theory. However, different experimental factors such as $\mathrm{pH}$ of acid solution, incorporation of mineral admixture and curing condition all have great influence on the corrosion depth-time kinetic equation. 
For the $\mathrm{pH}$ value of acid corrosion solution, the decrease of $\mathrm{pH}$ would lead to a sharp increase of acid ion, which inevitably results in the increased corrosion rate. Concerning the influence of mineral admixture, the experimental results indicated that as the incorporation of mineral admixture, the $k$ value of the kinetic equation decreased and the corrosion depth reduced. This may be mainly attributed to improved pore structure and phases constituent, as well as the decreased content of $\mathrm{Ca}(\mathrm{OH})_{2}$ after addition of FA [55-57]. Figure 14 displays the Xray diffraction analysis results of the corroded cement paste and cement paste incorporated with FA. As revealed in Fig. 14 (a), the X-ray diffractogram of cement paste is dominated by amorphous peak, with a hump at $\sim 15$ to $40^{\circ} 2 \theta$. This may be amorphous silica gel generated by the reaction between hydrated production and the corrosion solution. Sharp peaks could also be detected by X-ray diffraction analysis. Quartz and bassanite are found to be the major crystalline phases in the corroded cement paste. The quartz may be introduced by the raw materials and the presence of bassanite may be attributed to the corrosion of the $\mathrm{SiO}_{4}{ }^{2-}$. Compared with the corroded cement paste, after incorporated with fly ash, more sharp peaks can be found in Fig. 14 (b). It

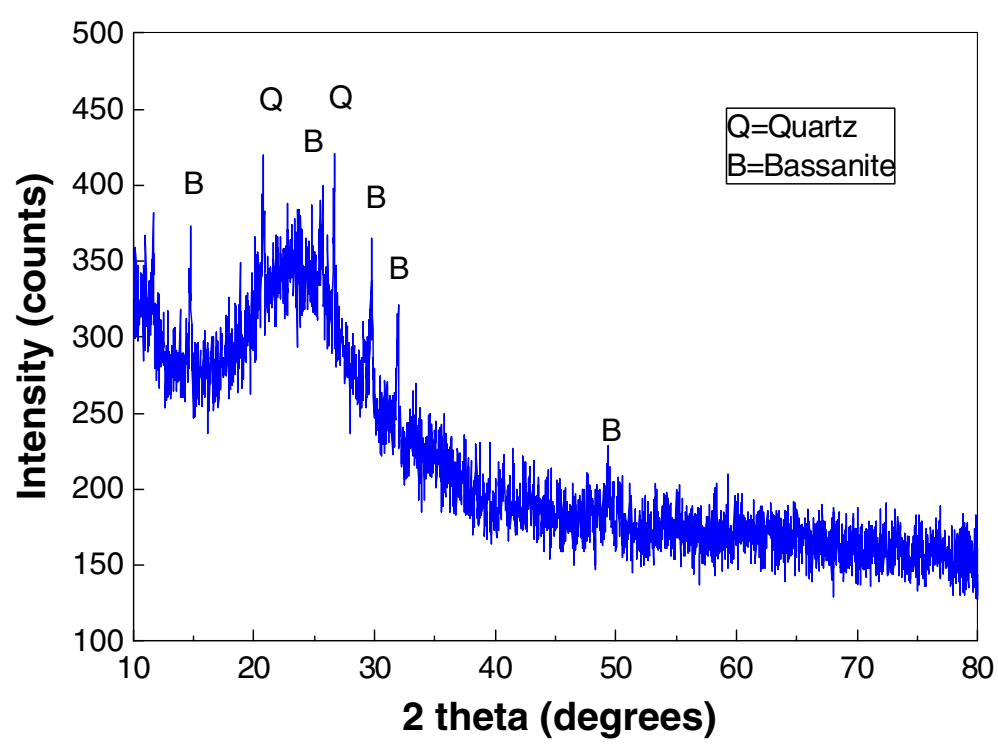

(a) $100 \%$ Cement

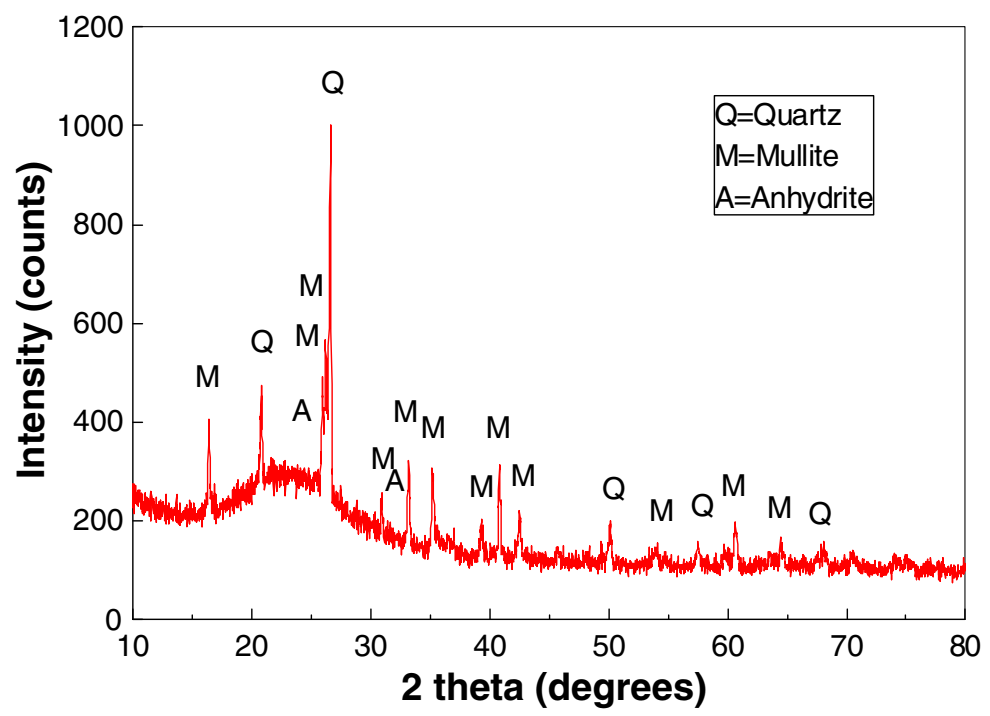

(b) $70 \% \mathrm{C}+30 \% \mathrm{FA}$

Fig. 14 X-ray diffractograms of corroded cement pastes 


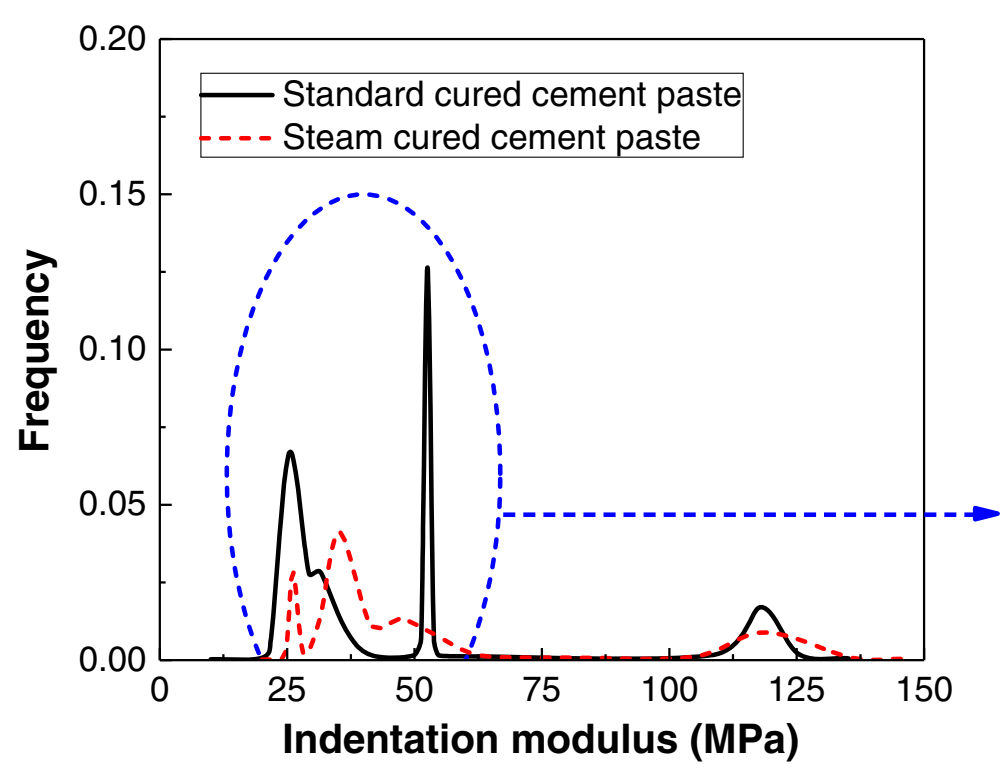

(a) Indentation modulus frequency distribution

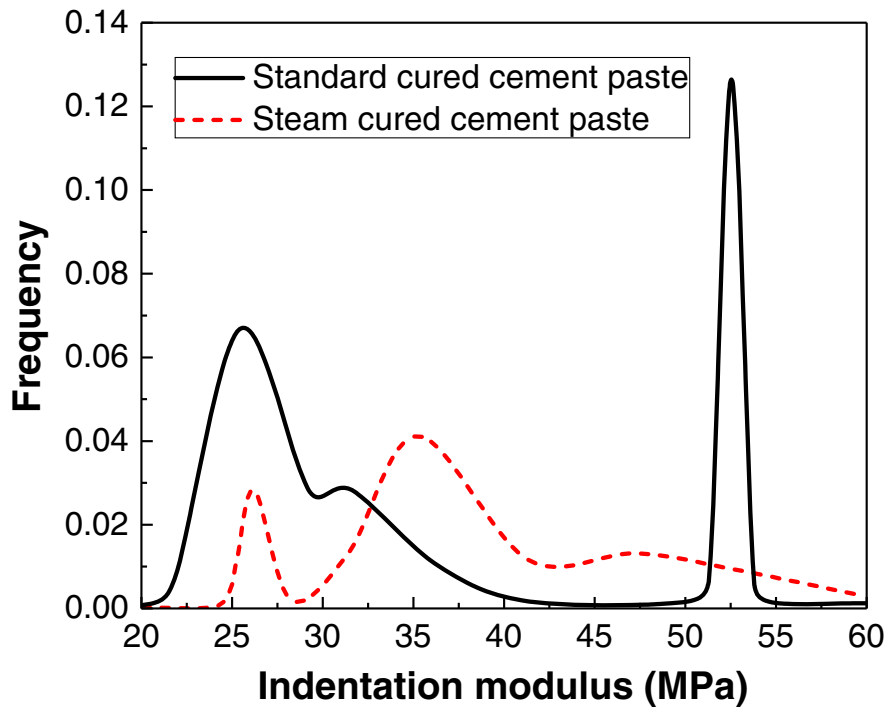

(b) Detailed indentation modulus frequency distribution

Fig. 15 Indentation modulus frequency distribution of phases under different curing conditions and ages

indicates the increase in the types of crystalline phase in this system. In addition to quartz and anhydrite, mullite could also be found, which may be introduced by fly ash. Unlike to crystals such as $\mathrm{C}_{3} \mathrm{~A}$ and $\mathrm{C}_{2} \mathrm{~A}$ in clinker, crystals in fly ash are less reactive. The more inert crystalline phases presented also can support the findings that the corrosion resistance of cement paste can be improved by FA. The inert constituents such as mullite and quartz in FA can fill in the microstructure of hydrated system and do not participate in the following chemical reaction and chemical corrosion reaction.
In terms of the influence of different condition of acid solution soaking and soaking-drying cycle on the corrosion depth-time kinetic equation, it mainly results from their influence on the corrosion reaction. The soaking time of the specimen in the acid solution soaking condition is longer than that in acid solution soaking-drying cycle, which leads to higher $t$ index. However, for specimen under the acid solution soaking-drying cycle temperature of under $60^{\circ} \mathrm{C}$, the high temperature increased the corrosion reaction, which results in bigger $k$ value presented in this case than only under acid solution soaking. 
Table 4 Volume fraction of different phases under different curing conditions

\begin{tabular}{lllll}
\hline Curing regimes & LD C-S-H & HD C-S-H & CH & Clinker \\
\hline Standard curing & $23.23 \%$ & $21.77 \%$ & $15.91 \%$ & $39.08 \%$ \\
Steam curing & $4.07 \%$ & $35.68 \%$ & $11.49 \%$ & $48.76 \%$ \\
\hline
\end{tabular}

The corrosion rate of the steam-cured specimens are larger than the specimens under standard curing, which may be a consequence of the changed hydrated products properties, volume fraction and pore structure. Figure 15 depicts the statistic nanoindentation results of different hydrated phases in the $28 \mathrm{~d}$ steam-cured specimens and $28 \mathrm{~d}$ standard-cured specimen. As revealed in Fig. 15, different peaks presented for phases of different kinds of specimens. The indentation modulus of the C-S-H gels in this study are quite similar to other studies [58-60], but the slightly greater indentation modulus of the $\mathrm{Ca}(\mathrm{OH})_{2}$ was obtained, which might associate with the different testing condition. In terms of $\mathrm{Ca}(\mathrm{OH})_{2}$, the indentation modulus of it in the standard-cured specimen is larger than in the $1 \mathrm{~d}$ and $28 \mathrm{~d}$ steam-cured specimens. However, both the indentation modulus of the HDC-S-H and LDC-S-H of standard-cured specimen are slightly lower than the $1 \mathrm{~d}$ steam-cured and $28 \mathrm{~d}$ steamcured specimens. These results indicated that under steam curing the nanomechanical properties of the major hydrated products, the $\mathrm{Ca}(\mathrm{OH})_{2}$ and the C-S-H, were different from that under standard curing, which might affect the durability of the corresponding specimens. Besides, as revealed in Table 4, there are different volume fractions for different phases under different curing conditions. Both the content of C-S-H and $\mathrm{Ca}(\mathrm{OH})_{2}$ in steam-cured specimen are less than that in standard-cured specimen, which means lower hydration degree. This may be also one of the important reasons leading to the increased corrosion rate presented in steam-cured specimen.

\section{Conclusions}

Based on the analysis of different effect factors and performance comparison between specimens under different conditions, the appearance, compressive strength and deteriorative kinetic of steam-cured paste and concrete specimens subjected to acid solution soakingdrying cycle were investigated. The main conclusions can be drawn as follows:

(1) The corrosion depth of both steam-cured cement paste and concrete increases with treatment duration in acidic solution or soaking-drying treatment and fits well with the kinetics equation, but the corrosion regularity and mechanism are different between cement paste and concrete.
(2) The addition of FA and a lesser extent GGBS has significant positive effects on the anti-corrosion ability of cement paste and concrete. Designing of concrete with suitable mineral admixture would be a potential way to develop concrete that can service in severer environment.

(3) Comparing with the steam-cured concrete and cement paste only subjected to soaking in acidic solution, the specimens under the treatment of soaking and drying cycles exhibit much higher corrosion depth and increases in the corrosion rate.

(4) The steam-cured cement paste and concrete display higher corrosion rate than the standard-cured counterparts regardless of the curing condition, indicating the challenges for applying of steam-cured concrete in corrosion environment.

(5) The undesirable performance of steam-cured concrete in coupled acid attack and drying action environment calls for optimal design in future research to ensure the safety of it, which can be typically devoted from aspects such as concrete material design (e.g. admixture), component design (e.g. composite component) and developing coating technology.

\section{Abbreviations}

A: Anhydrite; B: Bassanite; $C_{2} A$ : Dicalcium aluminate; $C_{3} A$ : Tri calcium aluminate; $\mathrm{CH}$ : Calcium Hydroxide; C-S-H: Calcium Silicate Hydrate; FA: fly ash; G: Limestone; GGBS: ground granulated blast-furnace slag; M: Mullie; PDF: Probability density function; Q: Quartz; S: Sand

\section{Acknowledgments}

The authors would like to acknowledge the financial support from National Natural Science Foundation of China (11790283, 51820105014 and 51808133) and China Railway Corporations (U1534207). The authors also would like to acknowledge the funding from the Australian Research Council (DE150101751), Australia and National Engineering Laboratory for Highspeed Railway Construction, Central South University (HSR2017001).

\section{Authors' contributions}

GL, YX, WL, ZL and LQ carried out the experiments, GL, YX, WL and JZ analyzed the test results. GL, YX and WL drafted the manuscript. All authors read and approved the final manuscript.

Funding

National Natural Science Foundation of China (11790283), China Railway Corporations (U1534207), Australian Research Council (DE150101751), National Engineering Laboratory for High-speed Railway Construction, Central South University (HSR2017001).

\section{Availability of data and materials}

Data and materials will be made available upon reasonable request to the corresponding author.

\section{Competing interests}

The authors declare that they have no competing interests.

\section{Author details}

${ }^{1}$ School of Civil Engineering, Central South University, Changsha 410075, Hunan, China. ${ }^{2}$ Center for Green Technology, School of Civil \& Environmental Engineering, University of Technology Sydney, Sydney, NSW 2007, Australia. 
Received: 30 July 2019 Accepted: 10 October 2019

Published online: 23 March 2020

\section{References}

1. $\operatorname{Vr}$ Z, Bajza A (2001) Acidic attack of cement based materials - a review.: part 1. Principle of acidic attack. Constr Build Mater 15(8):331-340

2. Gjørv OE (2014) Durability design of concrete structures in severe environments. Boca Raton: CRC Press

3. Girardi F, Di Maggio R (2011) Resistance of concrete mixtures to cyclic sulfuric acid exposure and mixed sulfates: effect of the type of aggregate. Cem Concr Compos 33(2):276-285

4. Khan HA, Castel A, Khan MS, Mahmood AH (2019) Durability of calcium aluminate and sulphate resistant Portland cement based mortars in aggressive sewer environment and sulphuric acid. Cem Concr Res 124: 105852

5. Barr P, Stanton J, Eberhard M (2005) Effects of temperature variations on precast, prestressed concrete bridge girders. J Bridg Eng 10(2):186-194

6. Li M, Wang Q, Yang J (2017) Influence of steam curing method on the performance of concrete containing a large portion of mineral admixtures. Adv Mater Sci Eng 2017:1-11.

7. Hanif A, Kim Y, Lu Z, Park C (2017) Early-age behavior of recycled aggregate concrete under steam curing regime. J Clean Prod 152:103-114

8. Kim Y, Park W, Hanif A (2019) Steam-cured recycled aggregate concrete incorporating moderately high early strength cement: effect of binder content and curing conditions. SN Appl Sci 1(5):445

9. Hanif A, Kim Y, Lee K, Park C, Sim J (2017) Influence of cement and aggregate type on steam-cured concrete-an experimental study. Mag Concr Res 69(13):694-702

10. Patel H, Bland C, Poole A (1995) The microstructure of concrete cured at elevated temperatures. Cem Concr Res 25(3):485-490

11. Kjellsen KO, Detwiler RJ, Gjørv OE (1990) Pore structure of plain cement pastes hydrated at different temperatures. Cem Concr Res 20(6):927-933

12. Long G, He Z, Omran A (2012) Heat damage of steam curing on the surface layer of concrete. Mag Concr Res 64(11):995-1004

13. Shen P, Lu L, He Y, Rao M, Fu Z, Wang F, Hu S (2018) Experimental investigation on the autogenous shrinkage of steam cured ultra-high performance concrete. Constr Build Mater 162:512-522

14. Long G, Yang J, Xie Y (2017) The mechanical characteristics of steam-cured high strength concrete incorporating with lightweight aggregate. Constr Build Mater 136:456-464

15. Ramezanianpour A, Khazali M, Vosoughi P (2013) Effect of steam curing cycles on strength and durability of SCC: a case study in precast concrete. Constr Build Mater 49:807-813

16. M-f B, C-x Q, Guo X-j, X-y H (2011) Effects of steam curing on strength and porous structure of concrete with low water/binder ratio. Constr Build Mater 25(1):123-128

17. Gonzalez-Corominas A, Etxeberria M, Galindo A (2016) Steam curing influence on Fly ash high-performance recycled concrete. ACI Mater J 113(6)

18. Ramezanianpour A, Esmaeili K, Ghahari S, Ramezanianpour A (2014) Influence of initial steam curing and different types of mineral additives on mechanical and durability properties of self-compacting concrete. Constr Build Mater 73:187-194

19. Huang $X$, Hu S, Wang F, Yang L, Rao M, Mu Y, Wang C (2019) The effect of supplementary cementitious materials on the permeability of chloride in steam cured high-ferrite Portland cement concrete. Constr Build Mater 197:99-106

20. Yan X, Jiang L, Guo M, Chen Y, Song Z, Bian R (2019) Evaluation of sulfate resistance of slag contained concrete under steam curing. Constr Build Mater 195:231-237

21. Xie S, Qi L, Zhou D (2004) Investigation of the effects of acid rain on the deterioration of cement concrete using accelerated tests established in laboratory. Atmos Environ 38(27):4457-4466

22. Beddoe RE, Dorner HW (2005) Modelling acid attack on concrete: part I. the essential mechanisms. Cem Concr Res 35(12):2333-2339

23. Lanzón M, García-Ruiz P (2010) Deterioration and damage evaluation of rendering mortars exposed to sulphuric acid. Mater Struct 43(3):417-427

24. Fan Y, Hu Z, Zhang Y, Liu J (2010) Deterioration of compressive property of concrete under simulated acid rain environment. Constr Build Mater 24(10): 1975-1983
25. Zhang Y, Fan Y, Liu J, Cao X (2010) Experimental study on compressive performance of concrete C40 in simulated acid environment. J Build Mater 13(1):105-110

26. Franzoni E, Sassoni E (2011) Correlation between microstructural characteristics and weight loss of natural stones exposed to simulated acid rain. Sci Total Environ 412:278-285

27. Chen M-C, Wang K, Xie L (2013) Deterioration mechanism of cementitious materials under acid rain attack. Eng Fail Anal 27:272-285

28. Fan Y, Luan H (2013) Pore structure in concrete exposed to acid deposit. Constr Build Mater 49:407-416

29. Miyamoto S, Minagawa H, Hisada M (2014) Deterioration rate of hardened cement caused by high concentrated mixed acid attack. Constr Build Mater $67: 47-54$

30. Xiao J, Qu W, Li W, Zhu P (2016) Investigation on effect of aggregate on three non-destructive testing properties of concrete subjected to sulfuric acid attack. Constr Build Mater 115:486-495

31. Pavlik V (1996) Corrosion of hardened cement paste by acetic and nitric acids part III: influence of water/cement ratio. Cem Concr Res 26(3):475-490

32. Pavlík V (1994) Corrosion of hardened cement paste by acetic and nitric acids part II: formation and chemical composition of the corrosion products layer. Cem Concr Res 24(8):1495-1508

33. Song H-W, Saraswathy V (2006) Studies on the corrosion resistance of reinforced steel in concrete with ground granulated blast-furnace slag-an overview. J Hazard Mater 138(2):226-233

34. Mekonnen A, Mandal J (2017) Model studies on bamboo-geogrid reinforced fly ash walls under uniformly distributed load. J Hazard Toxic Radioact Waste 22(2):04017030

35. Research CAoB (2009) GB/T 50082-2009 standard for test methods of longterm performance and durability of ordinary concrete. Beijing: China Architecture \& Building Press Beijing

36. Gao Y, Zhang Y, C H, Z L (2012) Nanomechanical properties of individual phases in cement mortar analyzed using nanoindentation coupled with scanning electron microscopy. J Chin Ceram Soc 40(11):1559-1563

37. Hu C, Li Z (2015) Property investigation of individual phases in cementitious composites containing silica fume and fly ash. Cem Concr Compos 57:17-

38. Hu C, Li Z, Gao Y, Han Y, Zhang Y (2014) Investigation on microstructures of cementitious composites incorporating slag. Adv Cem Res 26(4):222-232

39. Oliver WC, Pharr GM (1992) An improved technique for determining hardness and elastic modulus using load and displacement sensing indentation experiments. J Mater Res 7(6):1564-1583

40. Xiao J, Li W, Sun Z, Lange DA, Shah SP (2013) Properties of interfacial transition zones in recycled aggregate concrete tested by nanoindentation. Cem Concr Compos 37:276-292

41. Li W, Xiao J, Kawashima S, Shekhawat GS, Shah SP (2015) Experimental investigation on quantitative Nanomechanical properties of cement paste. ACI Mater J 112(2):229-238

42. Li W, Kawashima S, Xiao J, Corr DJ, Shi C, Shah SP (2016) Comparative investigation on nanomechanical properties of hardened cement paste. Mater Struct 49(5):1591-1604

43. Luo Z, Li W, Wang K, Shah SP (2018) Research progress in advanced nanomechanical characterization of cement-based materials. Cem Concr Compos 94:277-295

44. Constantinides G, Ravi Chandran KS, UIm FJ, Van Vliet KJ (2006) Grid indentation analysis of composite microstructure and mechanics: principles and validation. Mater Sci Eng A 430(1-2):189-202. https://doi.org/10.1016/j. msea.2006.05.125

45. Hu C, Li Z (2015) A review on the mechanical properties of cement-based materials measured by nanoindentation. Constr Build Mater 90:80-90

46. Brevett CA, Sumpter KB, Nickol RG (2009) Kinetics of the degradation of sulfur mustard on ambient and moist concrete. J Hazard Mater 162(1):281291

47. de Almeida Melo Filho J, de Andrade SF, Toledo Filho RD (2013) Degradation kinetics and aging mechanisms on sisal fiber cement composite systems. Cem Concr Compos 40:30-39

48. S-h Y, Yang Y-f, T-s Z, G-f G, Yu F (2015) Effect of carbonic acid water on the degradation of Portland cement paste: corrosion process and kinetics. Constr Build Mater 91:39-46

49. Ghazy A, Bassuoni M (2017) Resistance of concrete to different exposures with chloride-based salts. Cem Concr Res 101:144-158 
50. Zhakin Al (2017) The high-temperature and radiative effect on concrete. High Temp 55(5):767-776

51. Yang Q, Yang Q, Zhu P (2003) Scaling and corrosion resistance of steamcured concrete. Cem Concr Res 33(7):1057-1061

52. De Muynck W, De Belie N, Verstraete W (2009) Effectiveness of admixtures surface treatments and antimicrobial compounds against biogenic sulfuric acid corrosion of concrete. Cem Concr Compos 31(3):163-170

53. Gu L, Visintin P, Bennett T (2017) Evaluation of accelerated degradation test methods for cementitious composites subject to sulfuric acid attack; application to conventional and alkali-activated concretes. Cem Concr Compos 87:187-204

54. Pavlik V (1994) Corrosion of hardened cement paste by acetic and nitric acids part I: calculation of corrosion depth. Cem Concr Res 24(3):551-562

55. Nnadi EO, Lizarazo-Marriaga J (2012) Acid corrosion of plain and reinforced concrete sewage systems. J Mater Civ Eng 25(9):1353-1356

56. Pacheco-Torgal F, Jalali S (2009) Sulphuric acid resistance of plain, polymer modified, and fly ash cement concretes. Constr Build Mater 23(12):34853491

57. Donatello S, Palomo A, Fernández-Jiménez A (2013) Durability of very high volume fly ash cement pastes and mortars in aggressive solutions. Cem Concr Compos 38:12-20

58. Sorelli L, Constantinides G, Ulm F-J, Toutlemonde F (2008) The nanomechanical signature of ultra high performance concrete by statistical nanoindentation techniques. Cem Concr Res 38(12):1447-1456

59. Randall NX, Vandamme M, Ulm F-J (2009) Nanoindentation analysis as a two-dimensional tool for mapping the mechanical properties of complex surfaces. J Mater Res 24(3):679-690

60. Zhu W, Hughes JJ, Bicanic N, Pearce CJ (2007) Nanoindentation mapping of mechanical properties of cement paste and natural rocks. Mater Charact 58(11-12):1189-1198

\section{Publisher's Note}

Springer Nature remains neutral with regard to jurisdictional claims in published maps and institutional affiliations.

\section{Submit your manuscript to a SpringerOpen ${ }^{\circ}$ journal and benefit from:}

- Convenient online submission

- Rigorous peer review

- Open access: articles freely available online

High visibility within the field

- Retaining the copyright to your article

Submit your next manuscript at $\boldsymbol{\nabla}$ springeropen.com 